\title{
Etiological factors in young patients with Retinal Vein Occlusion
}

\author{
Serhad Nalcaci' ${ }^{1}$ Cumali Degirmenci², \\ Cezmi Akkin ${ }^{3}$, Jale Mentes ${ }^{4}$
}

\begin{abstract}
Objective: To present the etiological factors of patients with Retinal Vein Occlusion (RVO) under the age of 50 years.

Methods: The study was conducted at Ege University Medicine Faculty Department of Ophthalmology. The clinical records of patients with RVO under the age of 50 seen between January 2014 and March 2018 were analyzed retrospectively. Forty patients comprised the study. Detailed ophthalmologic examination was performed. Past medical history, drug use, thrombophilic features, hyperviscosity syndromes and pathologies that may cause vasculitis were noted.

Results: Forty patients, 22 (55\%) male and 18 (45\%) female, were included. Mean age was $41.6 \pm 10.01$ years. Mean intraocular pressure and best-corrected visual acuity were $16.8 \pm 5.47 \mathrm{mmHg}$ and $0.76 \pm 0.64 \log M A R$, respectively. Hyperhomocystenemia (15 patients, 37.5\%), Behçet's disease (three patients, 7.5\%), diabetes and/or hypertension (16 patients, $40 \%$ ), methylenetetrahydrofolate reductase gene mutation (11 patients, $27.5 \%$ ), prothrombin gene mutation (four patients, $10 \%$ ) and factor $V$ Leiden mutation (five patients, $12.5 \%$ ) were present among the patients as etiological factor. Multiple etiological factors were detected in 11 (27.5\%) patients. Factor V Leiden mutation and methylenetetrahydrofolate reductase gene mutation were detected in one patient (2.5\%) with Behçet's disease. Four patients with diabetes and/or hypertension also had hyperhomocystenemia and one of them had additionally prothrombin gene mutation. Two patients with methylenetetrahydrofolate reductase gene mutation also had a factor $\mathrm{V}$ Leiden mutation and one of them had additionally a prothrombin gene mutation. Three patients with methylenetetrahydrofolate reductase gene mutation also had hyperhomocystenemia and one patient with prothrombin gene mutation also had methylenetetrahydrofolate reductase gene mutation.

Conclusions: Etiological factors that might result in RVO in young individuals should be investigated in detail. Targeted therapies may help to prevent development of new RVOs and potential vascular problems in other organs.
\end{abstract}

KEYWORDS: Etiological factors, Retinal vein occlusion, Young patients.

How to cite this:

doi: https://doi.org/10.12669/pjms.35.5.546

Nalcaci S, Degirmenci C, Akkin C, Mentes J. Etiological factors in young patients with Retinal Vein Occlusion. Pak J Med Sci. 2019;35(5):1397-1401. doi: https://doi.org/10.12669/pjms.35.5.546

This is an Open Access article distributed under the terms of the Creative Commons Attribution License (http://creativecommons.org/licenses/by/3.0), which permits unrestricted use, distribution, and reproduction in any medium, provided the original work is properly cited.

Correspondence:

Dr. Serhad Nalcaci,

Ege University Faculty of Medicine,

Department of Ophthalmology,

35040 Bornova,

Izmir, Turkey.

Email: serhadnalcaci@hotmail.com

* Received for Publication

* Revision Received:

* Revision Accepted: *
February 10, 2019

June 7, 2019

June 26, 2019

\section{INTRODUCTION}

Retinal vein occlusion (RVO) is the second most common retinal vascular disease after diabetic retinopathy. ${ }^{1}$ Although RVO is frequently seen in people older than 65 years, it is an important reason of vision loss that may also affect the young people. It is more common in men. Retinal vein occlusions are classified as central, hemi-central and branch 
occlusions according to the level of occlusion. ${ }^{2}$ While the occlusion is at disc level in central and hemi-central vein occlusions, in branch retinal vein occlusion (BRVO) it is at arteriovenous crossing point. ${ }^{3}$ The prevalences of $\mathrm{BRVO}$ and central retinal vein occlusion (CRVO) are about $0.6 \%$ and $0.1 \%$, respectively. ${ }^{4}$

The most common risk factors of RVO are systemic vascular diseases (diabetes, hypertension, hyperlipidemia) and elder age ( $>65$ years) ${ }^{2,3} \mathrm{RVO}$ is affected by differentfactorsincluding the use of drugs (Oral Contraseptives (OCC), hormone treatments), various rheumatic diseases, infections, deficiency of protein $\mathrm{C}$, protein $\mathrm{S}$ and antithrombin that cause susceptibility to thrombophilia, antiphospholipid antibodies, hyperhomocysteinaemia, genetic mutations (Factor V Leiden mutation, MTHFR (methylenetetrahydrofolate reductase) mutation, prothrombin gene mutation) and hyperviscosity syndromes (polycythemia rubra, leukemia, lymphoma). ${ }^{5}$ These factors can play an important role especially in young RVO patients. Schockman et $a .^{6}$ reported that factor $\mathrm{V}$ Leiden and / or prothrombin mutation $(9 \%)$, low protein $S$ levels $(9 \%)$ and elevated homocysteine levels (23\%) were the predisposing risk factors in RVO patients.

In young patients, determining the factors that may cause predisposition to RVO may affect the progress of the disease positively by decreasing the recurrence of it or its potential occurrences in the other eye. Accordingly, the potential etiological factors that may cause RVO in young patients should undergo careful systemic examination and detailed laboratory analysis.

\section{METHODS}

The study was conducted at Ege University Medicine Faculty Department of Ophthalmology. The clinical records of patients who were diagnosed with RVO under the age of 50 between January 2014 and March 2018 were analyzed retrospectively. Forty patients comprised the study. The study was carried out by getting the approval of Ege University, Faculty of Medicine, Clinical Researches Ethical Committee and being in conformity with Helsinki Declaration and written informed consent forms were taken from all patients. The clinical findings, fundus photos and medical records of these patients were reviewed by two different retina experts. Based on these data, CRVO was identified as optic nerve head swelling, retinal hemorrhages in all four quadrants of the fundus with a dilated and tortuous retinal venous system. BRVO was identified as the presence of retinal hemorrhages and exudates after any arteriovenous crossing point with dilated and tortuous retinal veins in the said quadrant. The diagnoses were verified with fluorescein angiography in the consideration of venous filling defects and extended venous filling time.

Together with the demographic data of the patients such as age and gender, ophthalmological data such as the best corrected visual acuity (BCVA) evaluated by logarithm of the Minimum Angle of Resolution (logMAR), Intraocular Pressure (IOP) measured by Goldmann applanation tonometry, refractive error, type of vein occlusion and glaucoma history were recorded. Fundus photos, optic coherence tomography images and fluorescein angiography data of all patients were evaluated and recorded.

Besides these, the examinations performed for systemic diseases such as diabetes, hypertension, Behçet's disease and use of medicines (OCC etc.) were also recorded. Smokers were excluded from the study because the amount of smoking may vary widely among individuals. All patients were examined further in terms of mainly systemic hypertension, diabetes, hyperlipidemia and cardiovascular diseases and other thrombophilic features (hyperhomocysteinaemia, MTHFR mutation, factor $\mathrm{V}$ Leiden mutation, deficiency of protein $\mathrm{C}$, deficiency of protein $\mathrm{S}$, protein $\mathrm{C}$ resistance, prothrombin gene mutation, antiphospholipid syndrome) that may lead to RVO, hyperviscosity syndromes (leucemia, lymphoma, polycythemia, multipl myeloma) and other pathologies that may cause vasculitis (Behçet's disease, sarcoidosis, syphilis, systemic lupus erythematosus). Additionally, all of them were investigated with the consultation of relevant departments.

\section{RESULTS}

Twenty-two (55\%) patients were male and 18 $(45 \%)$ patients were female. The mean age was $41.6 \pm 10.01$ (range $22-50$ years). While CRVO was diagnosed in $18(45 \%)$ patients, BRVO was diagnosed in $22(55 \%)$ patients (Table-I).

The mean BCVA was $0.76 \pm 0.64 \log \mathrm{MAR}(0-2)$. This value was $0.52 \pm 0.28 \log$ MAR $(0.05-0.7)$ in patients with BRVO and as $0.89 \pm 0.67 \log$ MAR $(0$ 2) in patients with CRVO.

Mean IOP was $16.8 \pm 5.47 \mathrm{mmHg}(10-28)$ and there was one patient with glaucoma history. Six (15\%) patients were hypermetropic and 11 (27.5\%) 
Table-I: Demographic data of patients.

\begin{tabular}{ccc}
\hline & CRVO & BRVO \\
& $(n=18), n(45 \%)$ & $(n=22), n(55 \%)$ \\
\hline Gender & & \\
Male & $9(50 \%)$ & $13(59.1 \%)$ \\
Female & $9(50 \%)$ & $9(40.9 \%)$ \\
Age & & \\
$<30$ & $7(38.9 \%)$ & $3(13.6 \%)$ \\
$30-40$ & $3(16.7 \%)$ & $5(22.7 \%)$ \\
$41-50$ & $8(44.4 \%)$ & $14(63.6 \%)$ \\
Mean & $35.4 \pm 10.8$ & $42.00 \pm 9.4$ \\
\hline
\end{tabular}

CRVO, Central Retinal Vein Occlusion;

BRVO, Branch Retinal Vein Occlusion.

patients were myopic. There was no refractive error in $23(57.5 \%)$ patients. Other ocular causes of RVO like uveitis were not detected.

In the systemic etiological researches, there was an OCC usage history in two (5\%) patients (one CRVO, one BRVO). While two (9\%) of the BRVO patients had diabetes and eight $(36.3 \%)$ had hypertension, two $(11.1 \%)$ of the CRVO patients had diabetes and four $(22.2 \%)$ had hypertension. In two of these patients, BRVO was found as the first finding for Behçet's disease. The distribution of patients with respect to etiology and BRVO/CRVO is given in Table-II. The MTHFR gene mutation was in four $(36.3 \%)$ patients homozygous and in seven $(63.7 \%)$ patients heterozygous. The prothrombin gene mutation was in two $(50 \%)$ patients homozygous and in two $(50 \%)$ patients heterozygous. All $(100 \%)$ of the factor V Leiden gene mutations were heterozygous. Eleven $(27.5 \%)$ patients had multiple etiological factors. The distribution of the multiple etiological factors is given in Table-III.

All of these patients were brought under control in the relevant units for monitoring and treatment of these pathologies. The data obtained in this study for the management of young RVO cases are discussed below and compared with the literature.

\section{DISCUSSION}

Retinal vein occlusion is rising by the increase of systemic vascular risk factors in elderly age and
Table-II: Distribution of Etiological Factors.

\begin{tabular}{lccc}
\hline & $\begin{array}{c}\text { CRVO } \\
(n=18)\end{array}$ & $\begin{array}{c}\text { BRVO } \\
(n=22)\end{array}$ & $\begin{array}{c}\text { TOTAL } \\
(n=40)(\%)\end{array}$ \\
\hline $\begin{array}{l}\text { Etiological Factor } \\
\text { Use of OCC }\end{array}$ & 1 & 1 & $2(5 \%)$ \\
Hyperhomocysteinaemia & 8 & 7 & $15(37.5 \%)$ \\
Behçet's Disease & - & 3 & $3(7.5 \%)$ \\
MTHFR gene mutation & 5 & 6 & $11(27.5 \%)$ \\
Prothrombin mutation & 3 & 1 & $4(10 \%)$ \\
Factor V Leiden mutation & 2 & 3 & $5(12.5)$ \\
Diabetes mellitus & 2 & 2 & $4(10 \%)$ \\
Hypertension & 4 & 8 & $12(30 \%)$ \\
Glaucoma & 1 & - & $1(2.5 \%)$ \\
\hline
\end{tabular}

CRVO, Central Retinal Vein Occlusion;

BRVO, Branch Retinal Vein Occlusion;

OCC, Oral Contraceptives;

MTHFR, Methylenetetrahydrofolate reductase.

especially systemic hypertension is the vascular pathology that is most associated with RVO in this group. ${ }^{2}$ However distribution of risk factors in RVO patients under the age of 50 years is varying significantly and should be evaluated in a broader perspective. This study presents the etiological research results in terms of RVO in young RVO cases who were diagnosed before the age of 50 years.

In the pathogenesis of retinal vein occlusion, Virchow's triad defined as hemodynamic changes (venous stasis), degenerative changes in vein walls and increased thrombosis trend is important. ${ }^{2}$ The most important factors in retinal vein occlusion are elder age and systemic vascular diseases. These risk factors come into prominence in RVO cases above the age of 65 . Hayreh et al. ${ }^{7}$ determined that $51 \%$ of RVO cases were elder than 65 years.

In the development of retinal vein occlusion another risk factor is gender. As in other vascular diseases, male patients are more susceptible to RVO. In their studies consisting of 103 cases, Fong et al. ${ }^{8}$ reported that $64 \%$ of the patients were male. Also in our study, $55 \%$ of the patients were male and $45 \%$ of them were female. However, there are

Table-III: Distribution of Multiple Etiological Factors.

\begin{tabular}{|c|c|c|c|c|c|c|c|c|c|c|c|}
\hline Patients/Etiological Factors & 1 & 2 & 3 & 4 & 5 & 6 & 7 & 8 & 9 & 10 & 11 \\
\hline Behçet's disease & $\mathrm{x}$ & & & & & & & & & & \\
\hline Diabetes and/or Hypertension & & $x$ & $\mathrm{x}$ & $x$ & $\mathrm{x}$ & & & & & & \\
\hline Hyperhomocystenemia & & $x$ & $x$ & $x$ & $\mathrm{x}$ & & & $x$ & $\mathrm{x}$ & $x$ & \\
\hline Prothrombin mutation & & & & & $\mathrm{x}$ & & $\mathrm{x}$ & & & & $\mathrm{x}$ \\
\hline MTHFR gene mutation & $x$ & & & & & $x$ & $\mathrm{X}$ & $x$ & $x$ & $x$ & $\mathrm{x}$ \\
\hline Factor V Leiden mutation & $x$ & & & & & $x$ & $\mathrm{X}$ & & & & \\
\hline
\end{tabular}

Pak J Med Sci September - October 2019 Vol. 35 No. 5 www.pjms.org.pk 1399 
studies which indicated that RVO is more common in female. ${ }^{9}$

Other important systemic risk factors for RVO are hypertension, hyperlipidemia and diabetes mellitus. According to data obtained from the studies, RVO is related with $48 \%$ hypertension, $20 \%$ hyperlipidemia and 5\% diabetes mellitus. ${ }^{2}$ In many previous studies, it was reported that RVO is especially seen in median and elder ages and related with hypertension, diabetes, hyperlipidemia, cardiovascular diseases and openangle glaucoma. ${ }^{2,5,10-12}$ In our study, hypertension was determined in $12(30 \%)$ patients, diabetes in four $(10 \%)$ and glaucoma in one $(2.5 \%)$ patient. These results were compatible with the literature.

Use of OCC is reported as an important risk factor for vascular occlusions especially in young female patients. ${ }^{13,14}$ Gynecologists generally suggest OCC usage for birth control. Additionally, since OCC is used for the regulation of menstrual cycle for in vitro fertilization, use of OCC in young age group significantly increased today. Although it was not clearly identified how use of OCC leads to $R V O$, there are many studies suggesting that it increases RVO risk. ${ }^{13,15,16}$ In our study, there were two $(5 \%)$ patients who were using OCC but did not have any additionally risk factors in terms of RVO.

Homocysteine is an amino acid that acts in methionine metabolism and which contains sulfur. Homocysteine converts into methionine by means of MTHFR enzyme. The mutations occurring in the gene that encodes this enzyme cause hyperhomocysteinaemia and lead to an increase in the risk of RVO and other neurological and cardiovascular diseases. ${ }^{17}$ While the heterozygous mutations in this gene are decreasing enzyme activity by $30 \%$, homozygous mutations decrease this by $60 \% .^{18}$ The relation between hyperhomocysteinaemia and RVO was reported in various studies. $\mathrm{Li}$ et $\mathrm{al}^{19}$ reported that there is a relation between plasma homocystein and RVO. However, they could not find a relation between MTHFR gene mutation and RVO. Starting from this point, it was suggested that the genetic factors alone are not enough to increase homocysteine levels and plasma homocysteine levels are influenced by age, gender, folate intake, smoking, vitamin B levels, systemic vascular diseases and use of anti-hypertensive medicines. ${ }^{20}$ In the literature, there are reported rates varying between $3-19 \%$ in terms of MTHFR gene mutation and hyperhomocysteinaemia relation. ${ }^{11,21}$ In our study, while there was hyperhomocysteinaemia in $15(37.5 \%)$ patients, MTHFR gene mutation was diagnosed in 11 (27.5\%) patients.

Different studies have reported that factor $\mathrm{V}$ Leiden and prothrombin gene mutations are effective in the development of RVO. ${ }^{6}$ Among these, factor $\mathrm{V}$ Leiden mutation is the genetic factor that causes thrombosis most frequently. ${ }^{22}$ This mutation is seen in white race in the frequency of $5 \% .{ }^{22}$ When this mutation occurs, protein $C$ becomes resistance to enzymatic degradation and causes hypercoagulability. It was reported that this mutation increases the risk of thrombosis 3-8 folds in individuals that are heterozygous and 80 folds in ones that are homozygous. It was seen that factor V Leiden mutation existed in $20 \%$ of patients with systemic vein thrombosis. ${ }^{22}$ Caprini et al. reported that there was factor $\mathrm{V}$ Leiden mutation in $17 \%$ of patients with deep vein thrombosis history and $27.3 \%$ of the patients with pulmonary embolism. ${ }^{22-24}$ Turello et al. detected heterozygous factor $\mathrm{V}$ Leiden mutation in $8.2 \%$ of the patients with RVO. ${ }^{25}$ In our study, while heterozygous factor $\mathrm{V}$ Leiden mutation was detected in five $(12.5 \%)$ patients, homozygous mutation was not detected. The reason of such diversity in the rates could be the fact that the studies had been implemented on different races.

Prothrombin gene mutation may increase the thrombosis risk by three folds by causing too much prothrombin production. It is the most frequent mutation seen after Factor V Leiden mutation. It was reported that the prothrombin gene mutation was seen in $5.5 \%$ of patients with thrombosis and $1.2 \%$ in normal individuals. ${ }^{22}$ Caprini et al. reported that this rate was $17 \%$ in patients with vein thrombosis history and $18.2 \%$ in patients with pulmonary embolism history. ${ }^{22}$ In a study that was carried out without making a distinction of young or elder age RVO, prothrombin gene mutation rate was determined as $4.2 \% .{ }^{25}$ Despite this fact, in our study such rate was found as 10\% (four patients). This result is supporting that genetic factors in terms of etiology are more effective in young patients with RVO.

Although retinal vein occlusion is frequently seen in patients above 65 years, it is a retinal vascular pathology that can be seen in early ages and that threatens the vision. While there are limited number of risk factors in elder ages regarding this pathology, risk factors in young patients are presenting a broader distribution. Starting from this point, etiological researches 
in a young RVO case should be considered more broadly including genetic tests. The positive results that can be obtained in terms of risk factors may ensure the treatment of these factors, which may cause thrombosis predisposition and may help to prevent development of new RVOs and potential vascular problems in other organs.

Conflicts of interest: None.

\section{REFERENCES}

1. Yau JW, Lee P, Wong TY, Best J, Jenkins A. Retinal vein occlusion: an approach to diagnosis, systemic risk factors and management. Intern Med J. 2008;38(12):904-910. doi: 10.1111/j.1445-5994.2008.01720.x.

2. Kolar P. Risk factors for central and branch retinal vein occlusion: a meta-analysis of published clinical data. J Ophthalmol. 2014:724780. doi: 10.1155/2014/724780.

3. Sinawat S, Bunyavee C, Ratanapakorn T, Sinawat S, Laovirojjanakul W, Yospaiboon Y. Systemic abnormalities associated with retinal vein occlusion in young patients. Clin Ophthalmol. 2017;11:441-447. doi: 10.2147/OPTH. S128341.

4. Klein R, Klein BE, Moss SE, Meuer SM. The epidemiology of retinal vein occlusion: the Beaver Dam Eye Study. Trans Am Ophthalmol Soc. 2000;98:133-141.

5. Hayreh SS, Zimmerman B, McCarthy MJ, Podhajsky P. Systemic diseases associated with various types of retinal vein occlusion. Am J Ophthalmol. 2001;131(1):61-77.

6. Schockman S, Glueck CJ, Hutchins RK, Patel J, Shah P, Wang P. Diagnostic ramifications of ocular vascular occlusion as a first thrombotic event associated with factor $\mathrm{V}$ Leiden and prothrombin gene heterozygosity. Clin Ophthalmol. 2015;4(9):591-600. doi: 10.2147/OPTH.S80714.

7. Hayreh SS, Zimmerman MB, Podhajsky P. Incidence of various types of retinal vein occlusion and their recurrence and demographic characteristics. Am J Ophthalmol. 1994;117(4):429-441.

8. Fong AC, Schatz H, McDonald HR, Burton TC, Maberley $\mathrm{AL}$, Joffe $\mathrm{L}$, et al. Central retinal vein occlusion in young adults (papillophlebitis). Retina. 1992;12(1):3-11.

9. Klein R, Moss SE, Meuer SM, Klein BE. The 15-year cumulative incidence of retinal vein occlusion: the Beaver Dam Eye Study. Arch Ophthalmol. 2008;126(4):513-518. doi: 10.1001/archopht.126.4.513.

10. Prisco D, Marcucci R. Retinal vein thrombosis: risk factors, pathogenesis and therapeutic approach. Pathophysiol Haemost Thromb. 2002;32(5-6):308-311.

11. Bucciarelli P, Passamonti SM, Gianniello F, Artoni A, Martinelli I. Thrombophilic and cardiovascular risk factors for retinal vein occlusion. Eur J Intern Med. 2017;44:44-48. doi: 10.1016/j.ejim.2017.06.022.

12. Luntz $\mathrm{MH}$, Schenker HI. Retinal vascular accidents in glaucoma and ocular hypertension. Surv Ophthalmol. 1980;25(3):163-167.

13. Aggarwal RS, Mishra VV, Aggarwal SV. Oral contraceptive pills: A risk factor for retinal vascular occlusion in in-vitro fertilization patients. J Hum Reprod Sci. 2013;6(1):79-81. doi: 10.4103/0974-1208.112389.
14. Eichinger S, Evers JLH, Glasier A, La Vecchia C, Martinelli I, Skouby S, et al. Venous thromboembolism in women: a specific reproductive health risk. Hum Reprod Update. 2013;19(5):471-482. doi: 10.1093/humupd/dmt028.

15. Thapa R, Paudyal G. Central retinal vein occlusion in young women: rare cases with oral contraceptive pills as a risk factor. Nepal Med Coll J. 2009;11(3):209-211.

16. Leff SP. Side-effect of oral contraceptives: occlusion of branch artery of the retina. Bull Sinai Hosp Detroit. 1976;24(4):227-229.

17. Brustolin S, Giugliani R, Felix TM. Genetics of homocysteine metabolism and associated disorders. Braz J Med Biol Res. 2010;43(1):1-7.

18. Miyaki K. Genetic polymorphisms in homocysteine metabolism and response to folate intake: a comprehensive strategy to elucidate useful genetic information. J Epidemiol. 2010;20(4):266-270.

19. Li D, Zhou M, Peng $X$, Sun H. Homocysteine, methylenetetrahydrofolate reductase $\mathrm{C677T}$ polymorphism, and risk of retinal vein occlusion: an updated meta-analysis. BMC ophthalmology. 2014;14:147. doi: 10.1186/1471-241514-147.

20. Nurk E, Tell GS, Vollset SE, Nygard O, Refsum H, Nilsen RM, et al. Changes in lifestyle and plasma total homocysteine: the Hordaland Homocysteine Study. Am J Clin Nutr. 2004;79(5):812-819.

21. Biancardi AL, Gadelha T, Borges WI, Vieira de Moraes H Jr, Spector N. Thrombophilic mutations and risk of retinal vein occlusion. Arq Bras Oftalmol. 2007;70(6):971-974.

22. Caprini JA, Glase CJ, Anderson CB, Hathaway K. Laboratory markers in the diagnosis of venous thromboembolism. Circulation. 2004;109(3):I4-8.

23. Rees DC, Cox M, Clegg JB. World distribution of factor V Leiden. Lancet. 1995;346(8983):1133-1134.

24. Slavik L, Krcova V, Hlusi A, Prochazkova J, Prochazka M, Ulehlova J, et al. Molecular pathophysiology of thrombotic states and their impact to laboratory diagnostics. Biomed Pap Med Fac Univ Palacky Olomouc Czech Repub. 2009;153(1):19-25.

25. Turello M, Pasca S, Daminato R, Dello Russo P, Giacomello $\mathrm{R}$, Venturelli $\mathrm{U}$, et al. Retinal vein occlusion: evaluation of "classic" and "emerging" risk factors and treatment. J Thromb Thrombolysis. 2010;29(4):459-464. doi: 10.1007/ s11239-009-0384-5.

\section{Authors' Contribution:}

SN: Conceived, designed and manuscript writing.

CD: Did data collection and editing of manuscript.

CA: Did review and final approval of manuscript.

JM: Did final approval of manuscript.

Authors:

1. Dr. Serhad Nalcaci, M.D.

2. Dr. Cumali Degirmenci, M.D.

3. Prof. Cezmi Akkin, M.D.

4. Prof. Jale Mentes, M.D.

1-4: Ege University Faculty of Medicine, Department of Ophthalmology, Izmir, Turkey. 